\title{
La otra presencia de España en el exterior: la cooperación internacional
}

\author{
M. ${ }^{\text {a CONCEPCIÓN YBARRA }}{ }^{*}$
}

\begin{tabular}{|c|c|}
\hline RESUMEN & ABSTRACT \\
\hline $\begin{array}{r}\text { La Constitución española de } 1978 \\
\text { proclama que «la nación española } \\
\text { tiene una voluntad definida de } \\
\text { colaborar en el fortalecimiento de } \\
\text { unas relaciones pacíficas y de eficaz } \\
\text { cooperación entre todos los pueblos } \\
\text { de la tierra» y para conseguirlo, las } \\
\text { Cortes han aprobado el } 7 \text { de julio } \\
\text { de } 1998 \text { la «Ley de la Cooperación } \\
\text { internacional para el Desarrollo». } \\
\text { Enreste artículo se explica la } \\
\text { problemática de dicha cooperación y } \\
\text { la Historia de la Unión Europea y la } \\
\text { de España respecto a su política de } \\
\text { ayuda al desarrollo. }\end{array}$ & $\begin{array}{l}\text { The spanish Constitution of } 1978 \\
\text { states that the Spanish Nation is willing } \\
\text { to colloborate in the strenthning of } \\
\text { pacific relationshiph and efective } \\
\text { cooperation between all countries in } \\
\text { earth and to achive this aim, the } \\
\text { Parlament has aproved the } 7 \text { th } \\
\text { of July } 1988 \text { the "International } \\
\text { Cooperation Law for the } \\
\text { Development". } \\
\text { This article explains the dificulties of } \\
\text { said cooperation and the History of the } \\
\text { European Union and Spain with } \\
\text { respect to their politic of help to the } \\
\text { mundial development. }\end{array}$ \\
\hline $\begin{array}{r}\text { PALABRAS CLAVE } \\
\text { Constitución española de } 1978 . \\
\text { Cooperación internacional de } \\
\text { Ayuda al Desarrollo. }\end{array}$ & $\begin{array}{l}\text { KEY WORDS } \\
\text { Spanish Constitution of } 1978 . \\
\text { International Cooperation } \\
\text { for the Development. }\end{array}$ \\
\hline
\end{tabular}

* UNED. 


\section{INTRODUCCIÓN}

La desaparición de los dos bloques enfrentados, en lo que ha dado por llamarse "Guerra Fria", y el crecimiento de un mundo multipolar están generando nuevos problemas, conflictos y desequilibrios en la esfera internacional que han propiciado cambios en los conceptos de la cooperación y de la ayuda al desarrollo internacional. El Estado español coopera con el exterior de forma múltiple: en política económica, social, cultural, técnica, científica, laboral, en defensa, etc. En este trabajo interesa resaltar la actuación española en política de ayuda a los paises subdesarrollados o en vías de desarrollo, y para ello analizaremos los últimos 15 años de:

\section{LA POLITICA ESPAÑOLA DE COOPERACIÓN PARA EL DESARROLLO}

En primer lugar, explicaremos el origen de la estructura orgánica de la cooperación española, según expresa el texto de la Ley de 1998 para la Cooperación Internacional para el Desarrollo.

En segundo lugar, nos referiremos a la problemática de la cooperación: las razones, los criterios y las actuaciones, así como las acciones horizontales de cooperación y los problemas actuales de los paises desarrollados que colaboran para lograr el bienestar de los países subdesarrollados.

A continuación, se presentará una breve Historia de la Unión Europea respecto a esta Cooperación Internacional y los escenarios prioritarios de actuación.

Finalmente, se analizará la Historia de la Cooperación internacional española de Ayuda al Desarrollo a través de los Reales Decretos del marco legal para la cooperación al desarrolio en España y la realidad de la ayuda española, tanto a nivel oficial como no gubernamental y se realizará una evaluación final, basados en los documentos publicados por las ONGs de mayor prestigio internacional.

1. Antecedentes de la estructura orgánica de la cooperación española para el desarrollo

"La política española de cooperación para el desarrollo tiene básicamente su origen en la declaración contenida en el preámbulo de la Constitución de 1978, en la que la Nación española proclama su voluntad de 
colaborar en el fortalecimiento de unas relaciones pacíficas y de eficaz cooperación entre todos los pueblos de la Tierra. La política de cooperación internacional para el desarrollo constituye un aspecto fundamental de la acción exterior de los Estados democráticos en relación con aquellos países que no han alcanzado el mismo nivel de desarrollo, basada en una cooperación interdependiente y solidaria de la sociedad internacional y de las relaciones que en ella se desarrollan" ${ }^{1}$.

\section{La problemática de la cooperación}

«El desarrollo constituye una empresa ambiciosa y compleja. Asegurar a todos los seres humanos, en todas las partes del mundo, las condiciones que permitan una vida digna y con sentido, implica un enorme esfuerzo humano y un profundo cambio en las políticas." ${ }^{2}$ Según el $/ n$ forme sobre Desarrollo Humano de la UNESCO, se considera que cel desarrollo es un proceso que aumenta la libertad efectiva de quienes se benefician de él para llevar a cabo aquello que, por una razón u otra, tienen motivos para valorar. Desde esta perspectiva, la pobreza no sólo implica carecer de bienes y servicios esenciales, sino también de oportunidades para escoger una existencia más plena, más satisfactoria, más valiosa y más preciada».

\section{A) Razones que tienen los países desarrollados para otorgar su cooperación al desarrollo}

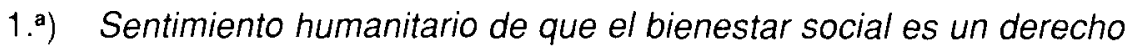
de todos los individuos. La mayoría de las personas, alejadas de cualquier fundamentalismo, sienten que todos los seres humanos deberían poseer, al menos, lo necesario para poder vivir en paz y en libertad. "La exigencia de mayor bienestar humano se está convirtiendo en imperiosa porque se ha comenzado a percibir que los fracasos y las expectativas frustradas de desarrollo han originado tensiones culturales y sociales en muchas sociedades. Estos fracasos, muchas veces, se han manifestado en: guerras civiles, regímenes autoritarios y asesinos que desestabilizan el propio proceso de desarrollo, por lo tanto se está llevando a cabo la revisión del sistema de

Ley 23/1998 de 7 de julio, de Cooperación Internacional para el Desarrollo.
Informe de la Comisión Mundial de Cultura y Desarrollo, págs. 14-16. París, septiembre de 1996. 
cooperación al desarrollo mundial. La cooperación entre diferentes pueblos con intereses y culturas distintos, se verá facilitada y los conflictos se mantendrán dentro de límites aceptables y constructivos, si todos pueden verse vinculados y motivados por compromisos compartidos. Por lo tanto, resulta imperativo definir un núcleo de principios y valores éticos comunes» ${ }^{3}$.

2. a) Desazón ante la pobreza mundial en medio de la opulencia. El contraste manifiesto entre las grandes riquezas que ostentan no sólo los países más desarrollados, sino los potentados de países pobres o en vías de desarrollo y las poblaciones más miserables que deben buscar día a día su supervivencia produce, en general, un malestar en las conciencias que conduce a plantearse el medio de arreglar tanta diferencia vital. El abismo entre ricos y pobres sigue agrandándose y sólo una política global de solidaridad logrará paliar esa diferencia.

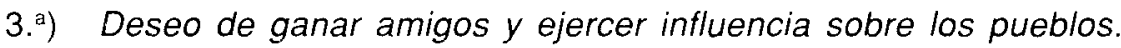
Muchos gobiernos e instituciones, laicas o religiosas, buscan la manera de alcanzar prestigio, amistad o poder político y económico entre los países menos desarrollados. "El desafío que tiene ante sí la humanidad es adoptar nuevas formas de pensar, actuar y organizarse en sociedad; en resumen, nuevas formas de vivir. El desafío consiste también en promover vías de desariollo diferentes... porque todavía no hemos aprendido a respetarnos plenamente, ni a compartir ni a colaborar ${ }^{4} "$. Nadie tiene derecho a imponer su «modo de vida». Alpha Oumar Konaré, Presidente de la República de Malí, manifestó en 1993 que «mientras una civilización ejerza sobre sus semejantes una presión política, intelectual y moral basada en aquello que la naturaleza y la historia le han concedido, no podrá haber esperanza de paz para la humanidad: la negación de la especificidad cultural de un pueblo equivale a la negación de su dignidad".

4. ${ }^{\mathrm{a})}$ Proteger las inversiones reales o potenciales. A fin de conservar y aumentar la preponderancia política, económica o ideológica, los gobiernos dominantes buscan la forma más conveniente de continuar ayudando a los países más propicios.

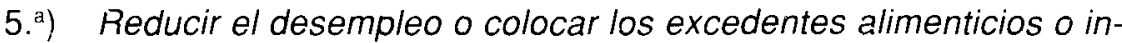
dustriales. Frecuentemente, la cooperación es una fórmula para exportar técnicos, trabajadores o parados y bienes de equipo, excedentes agrícolas, etc. a las poblaciones necesitadas que quedan en deuda material o espiritual con los países donantes.

Íbidem.

4 Javier Pérez de Cuéllar. Prólogo del Informe de la Comisión Mundial de Cultura y Desarrollo, pág. 11. 
Éstas son las principales razones que también se pueden aplicar a la actuación española, aunque algunas de ellas son claramente oportunistas.

B) Criterios en la elección de los países o poblaciones que recibirán la ayuda

1) A los países o situaciones más pobres. Éstos deberían ser, en definitiva, los primeros en recibir la mayor ayuda mundial, según los criterios más humanitarios y justos.

2) A los paises semidesarrollados. Con el fin de continuar la evolución ascendente de muchos países, es imprescindible que sigan recibiendo ayuda hasta alcanzar la verdadera independencia económica.

3) A países o casos con elevada marginalidad. Existen poblaciones que se encuentran en regiones ricas o con posibilidad de potenciar sus recursos pero que por diversas causas, políticas, religiosas o naturales, padecen graves lacras económicas, sociales y sanitarias que sólo se pueden paliar si reciben ayuda exterior.

La realidad es que la mayoría de los países desarrollados que cooperan (casi todos los paises pertenecientes a la OCDE ${ }^{5}$ ) actúan por razones comerciales, políticas o ideológicas. Pero el desarrollo que se está experimentando en diversas regiones, como muchas del Este Asiático, cuyos pueblos se mantienen fieles a sus valores dando muestras de que las tradiciones propias de cada cultura se pueden combinar con los recursos económicos, científicos y tecnológicos más modernos, es un buen ejemplo de que la cooperación entre los países más desarrollados y los más pobres o en vías de desarrollo, debe continuar e ir incrementándose día a día.

C) Actuaciones de los países donantes en el desarrollo de la humanidad

Según Jacques Delors, "la solidaridad debe ser nuestra consigna: cada uno debe asumir la parte de la responsabilidad colectiva que le corresponde". Los "pilares" éticos en los que se debe apoyar la actuación de los países donantes deben ser los siguientes:

a) Velar por los derechos humanos y las responsabilidades.

5 La Organización de Cooperación y Desarrollo Económico (OCDE) fue creada en 1960. 
b) Procurar que todos los pueblos alcancen la democracia y los elementos de la sociedad civil.

c) Proteger a las minorías.

d) Tener voluntad de resolver pacíficamente los conflictos y negociar con equidad intra e intergeneracional.

Las actuaciones de la cooperación deben ser complementarias, bien coordinadas y siempre desde un enfoque global realista. Esto es, que abarquen los campos económicos, sociales, políticos y culturales, y conecten con todos los sectores (educación, salud, agricultura e industria) a ser posible. Se debe potenciar tanto los recursos humanos como los técnicos.

La Comisión Mundial de Cultura y Desarrollo, fundada en 1992 por Federico Mayor Zaragoza, Director General de la UNESCO y dirigida por Javier Pérez de Cuéllar, ha manifestado que "es responsabilidad de todos los gobiernos hacer efectivos estos principios, y la aplicación de esta ética global exige también la participación de las empresas transnacionales, de las organizaciones internacionales y de la sociedad civil. ... El desarrollo sin contexto humano y cultural es un desarrollo sin alma. ... Ha llegado el momento de que Naciones Unidas lleve a la práctica lo que predica, a saber, una mayor participación de aquellos en cuyas vidas influyen las decisiones que se adoptan. Las organizaciones no gubernamentales, las fundaciones privadas, los representantes de los pueblos indígenas y las minorias culturales, las empresas y los sindicatos internacionales, los miembros de parlamentos y otros representantes de la sociedad civil también deben participar, si se quiere que Naciones Unidas aborde problemas estrechamente relacionados entre sí como los de la paz, la cultura, la pobreza, el medio ambiente, las cuestiones de género, los medios de comunicación y el desarrollo tecnológico".

\section{Acciones horizontales de cooperación}

Se consideran «acciones horizontales de cooperación" las siguientes:
a) Ayuda alimentaria.
b) Ayuda humanitaria de emergencia.
c) Cofinanciación de proyectos con ONG's.
d) Lucha contra la droga.
e) Lucha a favor de los Derechos Humanos.
f) Apoyo a la mujer y al desarrollo. 


\section{Problemas actuales}

En el presente siguen existiendo problemas muy difíciles de solucionar para que la Cooperación Internacional sea totalmente efectiva:

1. $\left.{ }^{\circ}\right)$ La Deuda externa.

2..$^{\circ}$ La falta de democracia.

3. ) La poca participación de la población en el desarrollo.

4. ) Alemania y el Reino Unido prefieren la ayuda bilateral, causa de desequilibrios en la Cooperación global.

\section{Historia de la cooperación al desarrollo de la Unión Europea}

Partiendo de la Carta de las Naciones Unidas respecto a la necesidad de que todos los pueblos se gobiernen por sí mismos y tengan acceso a una vida digna, el Tratado de Roma de 1957 (creación de la CEE) expuso las bases de una cooperación para el desarrollo de los países necesitados. Poco tiempo después se asociaron las colonias de Francia, Bélgica e italia con la CEE. A comienzos de los años 60 se consolidaba la independencia africana.

Los primeros acuerdos que se firmaron fueron:

- En Yaundé I (Camerún) 18 países francófonos negociaron el acuerdo en 1964 con preferencias comerciales reciprocas y cooperación financiera y técnica.

- En Yaundé $1 /, 1966$, se amplió el número de países que negociaron con la CEE.

- En Arusha (Tanzania), 1966, se firmaron acuerdos con Kenia, Tanzania y Uganda sobre la libre entrada de productos.

- En 1973 fue ampliada la CEE con Dinamarca, Reino Unido e Irlanda.

Escenarios tradicionales de la cooperación

Grupo ACP: Se constituyó en 1975 con 46 países de África, Caribe y Pacifico. Se firmó el Acuerdo Lomé 1 (Togo) para cinco años, sobre comercio, industria, cooperación financiera y regional.

Se firmó también el Protocolo del Azúcar. cuotas establecidas a precios garantizados. 
Se crearon los Fondos de Estabilización de exportaciones agrarias y mineras llamados STABEX Y SYSMIN.

En el Tratado de Lomé IV (1995) se acordó que los Fondos Europeos de Desarrollo fueran gestionados por la DGVII/ ${ }^{6}$ para el Acuerdo de Lomé.

La DGVIII gestiona también la ayuda alimentaria.

Otros escenarios de la cooperación europea

1) Norte de África: Maghreb (Marruecos, Túnez y Argelia): Acuerdos laborales y agrarios. Maschrek (Egipto, Líbano, Siria y Jordania): Infraestructuras y cooperación técnica.

2) Programas PHARE ${ }^{7}$ para Europa Central y del Este, y TACIS $^{8}$ para la $C E I$ (gestionados por la DGI).

3) Programas dentro del Grupo ALA: Asia y Latinoamérica. ASEAN: (Filipinas, Indonesia, Malasia, Birmania, Singapur y Tailandia). Reducciones arancelarias de un 20 a un 100\%. Apoyo a infraestructuras. América Latina: Cooperación bilateral con algunos paises (Brasil, Méjico, Colombia, Uruguay) y Sistema Generalizado de Preferencias, con el resto.

4) Acuerdo especial de cooperación con Mercosur (1995).

\section{Historia de la cooperación española al desarrollo}

En 1970 la ONU aprobó la Estrategia Internacional para el Segundo Decenio de las Naciones Unidas para el Desarrollo. Su objetivo era alcanzar el $0^{\prime} 7 \%$ PNB de los paises donantes.

En 1974 España comienza a participar en el Fondo Africano de Desarrollo. $Y$ también entra en el Banco interamericano de Desarrollo.

Por Real Decreto-ley 16/1976, de 24 de agosto, fue creado el Fondo de Ayuda al Desarrollo (FAD) que constituye un instrumento de la mayor im-

6 Dirección General (Comisión Europea).

Ayuda de la CE para la reestructuración económica inicialmente dirigida a Polonia y Hungria y ahora extendida al conjunto de Europa Orienta!.

3 Asistencia Técnica de la UE a los países de la Ex Unión Soviètica (Technical Assistance Community of Independant States). 
portancia dentro de la cooperación bilateral de España con paises menos desarrollados.

En 1981 España dejó de ser considerada por el Banco Mundial país receptor de ayuda internacional.

El Real Decreto 1485/1985 de 28 de agosto, por el que se estableció la estructura orgánica básica del Ministerio de Asuntos Exteriores, creó la Secretaria de Estado para la Cooperación Internacional y para Iberoamérica, de la que pasaron a depender todos aquellos Centros directivos y Organismos autónomos encargados de las relaciones culturales y económicas y de la cooperación científica y técnica.

Posteriormente, el Real Decreto 451/1986 de 21 de febrero creó la Comisión Interministerial de Cooperación Internacional (ClCl), como órgano de apoyo a la coordinación de la Administración del Estado en la materia. En este mismo Real Decreto, la Comisión Interministerial de Cooperación Internacional somete al Gobierno el Plan Anual de Cooperación (PACl).

Por Real Decreto $1527 / 1988$ de 11 de noviembre se creó la Agencia Española de Cooperación Internacional ( $A E C l)$, con el fin de reconducir la dispersión de competencias que caracterizaba a la cooperación española para el desarrollo. Este Organismo autónomo fue adscrito al Ministerio de Asuntos Exteriores y en él se concentraron las competencias relativas a la cooperación bilateral con los Países en Vías de Desarrollo (PVD), hasta entonces fragmentariamente atribuidas a diversos órganos. Esta misma norma fundó la Oficina de Planificación y Evaluación (OPE), unidad dependiente directamente del Secretario de Estado, encargada de la planificación y evaluación del programa español de ayuda al desarrollo, en particular de la elaboración y supervisión de los Planes Anuales de Cooperación Internacional.

La "Historia" de la presencia española entre los países donantes en la ayuda oficial al desarrollo puede decirse que se ha iniciado en los primeros años setenta, siempre de forma aislada, porque en 1970 cuando «la Asamblea General de las Naciones Unidas aprobó la Estrategia Internacional para el Segundo Decenio de las Naciones Unidas para el Desarro110 , en la que se incluía el objetivo de alcanzar el 0'7\% del PNB de los paises donantes en Ayuda Oficial al Desarrollo (AOD), España era aún un país receptor de este tipo de aportaciones" ". En 1974 España entró a participar en el «Fondo Africano de Desarrollo» y en 1976 en el «Banco In-

- Extracto del informe de Francisco AlbuRouerQue sobre La Cooperación Oficial de España al Desarrollo de febrero de 1992. (lCl, n. 702, págs. 144-159). 
teramericano de Desarrollo" y desde este año los créditos FAD fueron vinculados a la promoción de las exportaciones españolas de bienes de equipo y servicios a los países subdesarrollados.

Fue en la década de los ochenta cuando España se adhirió al "Convenio de Ayuda Alimentaria» y a la "Reserva Alimentaria Internacional de Emergencia" de la FAO, y accedió a los "Bancos Africano y Asiático de Desarrollo». En febrero de 1988 fue creada la Compañía Española de Financiación al Desarrollo (COFIDES), sociedad estatal que quedó enmarcada en el Plan de Fomento a la Exportación, con el claro objetivo "de incentivar la presencia del sector privado español en los países subdesarrollados, tanto para fomentar su producción como para promover la exportación de bienes, servicios y tecnología españoles" 10.

En cuanto a las aportaciones españolas de ayuda oficial al desarrollo (AOD) de los años 1979 y 1980, por tomar años ya algo significativos, alcanzaron un volumen del $0,08 \%$ del PNB, que significaba unos 160 millones de dólares USA en esos años. Durante los años siguientes de la década de los ochenta, los índices fueron subiendo un poco más $(0.13 \%$ del PNB), aunque en 1983 se produce un descenso hasta el 0'04\%, para los años posteriores subir tímidamente. Entre 1986 y 1990 los índices mediaron en torno al 0 '16\% del PNB. Estas ayudas se distribuyeron principalmente por América Latina y, en menor cuantía, por África.

\section{Actualidad de la cooperación internacional española}

El ingreso de España en el Comité de Ayuda al Desarrollo de la OCDE, en diciembre de 1991, ha significado un paso muy importante en la consolidación de la cooperación española con los países receptores de ayuda, porque el Estado español queda asi obligado a adaptar y a coordinar su política de cooperación para el desarrollo con la de los principales donantes del mundo, miembros del Comité.

Por Real Decreto 1141/1996, de 24 de mayo, se ha reestructurado la Agencia Española de Cooperación Internacional, completándose de esta forma la modificación ya realizada por el Real Decreto 2492/1994, de 23 de diciembre, que refundió los tres Institutos con rango de Dirección Generai, en los dos actuales, el Instituto de Cooperación Iberoamericana y el Instituto de Cooperación con el Mundo Árabe, Mediterráneo y Países en Desarrollo. Por su parte, el Real Decreto 795/1995, de 19 de mayo, en

10 íbidem. 
cumplimiento de lo dispuesto en la disposición adicional vigésimo novena de la Ley $42 / 1994$, de 30 de diciembre, había creado el Consejo de Cooperación para el Desarrollo, como órgano de participación de los diversos agentes sociales implicados en esta materia.

En 1995 se aprobaron la líneas para la Cooperación:

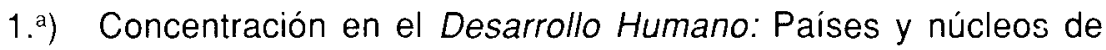
población más desfavorecidos.

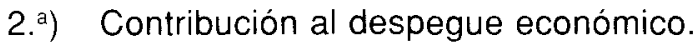

3. ${ }^{a}$ ) Concentración y especialización geográfica.

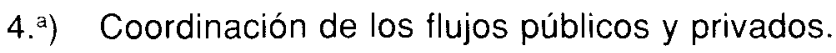

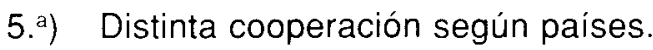

6. $\left.{ }^{a}\right)$ Coordinación con Organismos multilaterales.

7. a) Impacto medioambiental.

8. ${ }^{a}$ Especial participación de la mujer.

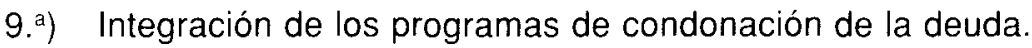

10. ${ }^{a}$ ) Cooperación Internacional con países industrializados y en desarrollo.

Cooperación multilateral

Aportaciones y cuotas a Organismos Internacionales:

1) La Unión Europea:

- Fondo Europeo de Desarrollo (FED). Canalizado hacia países signatarios de Lomé. Extrapresupuestario.

- Presupuesto Comunitario. América Latina. Asia. Cuenca Mediterránea.

Este de Europa y Ayuda Alimentaria.

2) Organismos Internacionales Financieros:

Banco Mundial ( $B M)$, Fondo Monetario Internacional ( $F M I)$, Banco Interamericano de Desarrollo $(B \mid D)$, Banco Asiático de Desarrollo $(B A s D)$, Banco Africano de Desarrollo (BAfD), Banco Europeo de Reconstrucción y Desarrollo $(D E R D)$. 
3) Organismos Internacionales no Financieros:

Cooperación cultural, técnica, cientifica, laboral... Agencia Espacial ... Europea, FAO ${ }^{11}$, UNICEF ${ }^{12}$, Laboratorio Europeo de Fisica ...

COOPERACIÓN BILATERAL. Componentes Básicos

1) FAD (Fondo de Ayuda al Desarrollo), 1976. Créditos y ayudas concesionales. Son $A O D$, superan el $35 \%$ concesional.

2) Programas/Proyectos. Asistencia técnica, cultural, científica, ayuda alimentaria, ayuda de emergencia, ayuda a las ONG's.

3) Cooperación Oficial Descentralizada. Comunidades Autónomas.

Entidades Locales. Municipios hermanados.

Últimas actuaciones gubernamentales en cooperación internacional para el desarrollo

El Real Decreto de 7 de julio de 1998 afirmaba que: «El estado actual de la cooperación española está significando un desarrollo extraordinario en lo que al incremento de recursos destinados a este fin se refiere y al impulso por parte de todas las Administraciones públicas, Administración Central, Comunidades Autónomas y Corporaciones locales, entre la sociedad civil de los valores de la cooperación y solidaridad internacional a través de programas y proyectos de sensibilización y concienciación de los ciudadanos en relación con los problemas globales y particulares relacionados con la cooperación al desarrollo, incluyendo el objetivo fijado por Naciones Unidas de destinar el 1 por 100 del PIB a los paises en vías de desarrollo".

Desarrollo de la Ley de 7 de julio de 1998
A) Principios:
1) El ser humano como destinatario.

if Organización de Naciones Unidas para la Alimentación y la Agricultura (Food and Agriculture Organization).

12 Fondo de Naciones Unidas para la Infancia (United Nations Children's Fund) 
2) Defensa y promoción de los Derechos Humanos.

3) Promover el desarrollo humano.

4) Crecimiento económico y redistribución de !a riqueza.

5) Respeto a los compromisos internacionales.

B) Prioridades geográficas:

Marco bilateral: Iberoamérica, paises árabes del Norte de África y Oriente Medio, y otros con lazos culturales o históricos (Filipinas).

Marco multilateral:

a) La Unión Europea (signatarios de Lomé, Iberoamérica y Asia, Este de Europa).

b) Organismos Internacionales Financieros (BM, FMS, BERD ${ }^{13}$ ).

c) Organismos Internacionales no Financieros (FAO, UNICEF).

Conceptos generales para la cooperación internacional para el desarrollo

1) Cooperación bilateral o multilateral.

2) Ayuda libre o ligada.

3) Donativos o préstamos:

- Vencimiento o período de amortización

- Coste del préstamo (interés)

- Periodo de carencia.

4) Programas o proyectos.

Condiciones necesarias para la ayuda oficial al desarrollo

Las condiciones necesarias para la Ayuda Oficial al Desarrollo (AOD), serán las que figuran en el Comité de Ayuda al Desarrollo (CAD) ${ }^{14}$ de la Organización para la Cooperación y el Desarrollo Económico (OCDE), y han quedado señaladas en la Ley de 1998:

a) Fondos del Sector Público: donaciones, préstamos o créditos blandos.

13 Banco Europeo de Reconstrucción y Desarrollo.

14 DAC: Development Assistance Committee 
b) El elemento de liberalidad ${ }^{15}$ en los créditos será de al menos el $25 \%$.

C) Tendrán como objetivo la mejora del desarrollo y el nivel de vida de 10.s PVD.

d) El país receptor estará incluido en la lista del CAD: (Los africanos, Estonia, Rusia, Emiratos Árabes, Kuwait).

El objetivo español es llegar lo antes posible al 0,28\% PNB de España.

La realidad de la ayuda (según Intermón)

Las anteriores exposiciones corresponden a las declaraciones oficiales del gobierno español, sin embargo, la realidad de la actuación española en cooperación internacional para el desarrollo de los países más deprimidos de la tierra es diferente según la Fundación Intermón ${ }^{16}$ : «1998 ha sido el año de culminación de un largo proceso de establecimiento de un marco legal para la cooperación al desarrollo en España». En este proceso el Consejo de Cooperación ha desarrollado una gran actividad a lo largo de 1997 y primer semestre del 98 . No obstante, también en este período se han acrecetando las desavenencias entre los dos Ministerios que manejan el grueso de la Cooperación, (Exteriores y Economía) y que ponen de manifiesto la falta de unidad de dirección en la Cooperación española. Intermón y las demás ONGs reclaman un Consejo que:

$\left.1^{\circ}\right)^{\circ)}$ Asegure la interlocución real entre los sectores más significativos de la cooperación para el desarrollo y los máximos responsables de la Cooperación oficial española (presidido por el Ministro de Asuntos Exteriores de una forma real).

2. ) Que sea operativo, eficiente en su funcionamiento, dotándole de los medios adecuados para el buen cumplimiento de las tareas que le son propias, $y$ asegurando un ritmo de trabajo continuado.

3. .) Que garantice su influencia en la orientación de la cooperación española, dándole la mayor importancia a sus dictámenes y resoluciones.

En 1999 se ha asistido a un gran debate, tanto en el Parlamento como en las ONGD, respecto a la Cooperación española de ayuda al desarrollo

15 Grado de concesionalidad relativa a la gratuidad y otras medidas favorables incorporada a un paquete crediticio, que para el deudor tiene mayores ventajas.

${ }_{16}$ Documentos Intermón: La Realidad de la Ayuda 1998/99, pág. 37. 
debido a la puesta en vigencia de la Ley de Cooperación y al proceso de reconstrucción en Centroamérica tras el paso del huracán Mitch. El punto fundamental ha sido la propuesta del primer Plan Director cuatrienal de la cooperación española. En él se plantean las estrategias y los objetivos para los próximos cuatro años. Ha sido muy discutido y ha implicado a todos los actores involucrados en dicha cooperación. El retraso de su puesta en marcha se debe a las reticencias del Ministerio de Economía. Se espera que se resuelvan con prontitud los problemas económicos y financieros para que se haga prioritaria la lucha contra la pobreza en el mundo.

El Banco Mundial ha manifestado que "alrededor de un tercio de la humanidad (unos mil trescientos millones de personas) vive hoy por debajo del umbral de la pobreza", es decir, con menos de un dólar al día. La ayuda oficial al desarrollo no es solución suficiente a este problema, pero puede contribuir a potenciar otras medidas. Para ello es necesario que incida en aquellos países y sectores más vulnerables. Este compromiso obliga a los países donantes a orientar su ayuda a la erradicación de la pobreza extrema, y a dirigirla hacia aquellas poblaciones y paises más pobres.

Es importante reconocer que cada día las ONGs de ayuda al desarrollo mundial, tanto las confesionales como las laicas, están alcanzando una gran presencia en los debates internacionales. Porque su labor se ha convertido en imprescindible para paliar muchas carencias que los gobiernos mundiales son incapaces de resolver.

Los indicadores que miden la orientación de la ayuda española a luchar contra la pobreza extrema son tres:

$\left.1 .^{\circ}\right)$ Porcentaje de la $A O D$ sobre el producto nacional bruto: cantidad mínima acordada por la ONU para la lucha efectiva contra la pobreza.

$\left.2 .^{\circ}\right) \quad A O D$ destinada a los países menos adelantados (PMA), aquéllos 48 países considerados los más pobres del mundo.

3. ) Ayuda destinada a sectores sociales básicos (SSB): son los sectores que inciden más directamente en las causas y consecuencias de la pobreza extrema.

España ha sido en 1997 uno de los pocos países que aumentaron su ayuda en ese año. Por primera vez, el porcentaje de AOD se situó por encima de la media del CAD $\left(0^{\prime} 22 \%\right)$. Aunque es necesario aclarar que España es el cuarto país, por la cola, del grupo de donantes y se encuentra muy por debajo de la media de la UE, que se sitúa en el $0,33 \%$. España aún no ha establecido un plan concreto para alcanzar el $0,7 \%$ sobre el PNB para los próximos años. Tampoco se ha puesto en práctica la reso- 
lución de la Comisión Europea sobre coordinación y coherencia de políticas, aunque ha mostrado interés por la coordinación en alguno de los países donde la cooperación española es mayor. Cuando se ponga en marcha el Plan Director podrá alcanzarse una mejora, no sólo en la coordinación sino también a nivel de cantidad y calidad de la ayuda.

La necesidad de una mayor coherencia entre las diferentes políticas exteriores que afectan al Sur es una antigua reivindicación de las ONGD, que ahora se ha visto apoyada por algunos gobiernos como el británico, que dedica una buena parte de su Libro Blanco a este tema. España ha dado pocos pasos, pero significativos, en este sentido. Ha habido avances concretos en algunas áreas, como es la prohibición de las minas antipersonas, aunque faltan algunas actuaciones como dotar fondos para el desminado y el apoyo a las víctimas. El anuncio, efectuado por el Presidente del Gobierno español en el último viaje emprendido por China y Filipinas, en julio de 2000, de poner en marcha en ese mismo mes de julio el Consejo de Política Exterior, instrumento para coordinar e impulsar las actividades de los departamentos del Ejecutivo con competencias en el extranjero, y la firma de un Tratado de Amistad y Cooperación con Filipinas ${ }^{17}$, también pueden significar un impulso a la presencia de España en esa zona del mundo.

Así mismo, existe hoy en día una mayor preocupación por el Comercio Justo (aquellos productos procedentes de los PVD a los que se aplican "márgenes comerciales razonables" en los mercados de los países desarrollados y que son producidos siguiendo unos principios de respeto a los derechos humanos, planteándose la necesidad de remunerar a los productores de los países de origen con una parte adecuada del precio pagado por el consumidor final ${ }^{18}$ ), procedimiento de estricta justicia social porque la «ayuda al desarrollo que se logra comprando esos productos es una fuente dinámica que, además de estimular su actividad económica, les hace menos dependientes de ayudas directas y subvenciones con un carácter de mayor subordinación" ${ }^{19}$.

Los retos para el futuro, respecto a la política española de cooperación para el desarrollo, son la condonación de la deuda exterior, la prevención de conflictos (en coordinación con otros paises de la UE) y la política pesquera (sobre todo con Marruecos). Algunos de los elementos

\footnotetext{
17 Este Tratado llevará anejo un programa financiero por importe de 21.300 millones de pesetas. La mitad de ellos será con cargo a los créditos FAD.

"Isabel de FElipe: La problemática del "comercio justo" de los países en desarrolio", pág. 15.

19 Íbidem.
} 
clave del caso español, en lo que a coherencia de políticas se refiere, son las implicaciones entre los intereses comerciales del pais donante y sus políticas de ayuda. España es el cuarto país con mayor nivel de ayuda ligada. Ésta puede significar una gran traba para el avance de la ayuda real al desarrollo porque, desde posturas próximas a las ONGD, se considera que:

A) Aumenta el coste de los bienes y servicios en más de un $30 \%$, y reduce el volumen real de la ayuda en 600 mil millones de pesetas anuales.

B) Impide a los paises en vias de desarrollo competir en igualdad de condiciones en la licitación de los créditos, y además limita las posibilidades de crecimiento de sus mercados.

C) Es un sistema costoso e ineficaz para fomentar las economías nacionales de los países donantes.

D) Reduce las posibilidades de coordinación entre los donantes.

E) Favorece aquellos proyectos que tengan carácter rentable, frente a los sociales "a fondo perdido".

F) Lleva, en muchos casos, a la donación de bienes o servicios que no son los prioritarios para el receptor, y aumenta su dependencia de los conocimientos y la tecnología del país donante.

G) Incrementa la burocracia en ambos sentidos.

H) La ayuda ligada es anacrónica, en tanto en cuanto va en contra de las medidas globales contra el proteccionismo.

Las consideraciones anteriores plantean un debate y un cuestionamiento difícil de resolver. Porque aunque desde los planteamientos anteriores se asegura la incompatibilidad radical entre las actuaciones de las empresas españolas, públicas y privadas, y la ayuda al desarrollo, sin embargo, es necesario que las autoridades y los empresarios tengan bien claro qué tipo de actividades se consideran fundamentales para el desarrollo de los países receptores, con propósito de obtener un crecimiento económico sostenido a medio y largo plazo, y cúales son en realidad las actuaciones aberrantes que persiguen muchas empresas para lograr para sí el máximo de beneficios y que puedan colocar sus excedentes de bienes y servicios. También hay que partir de la premisa de que España es todavía un país que tiene problemas económicos importantes (de pobreza, desempleo, marginalidad, deterioro industrial, ect.) y por lo tanto, canalizar una parte de su ayuda en forma "ligada" es otra opción que podría aumentar la cooperación empresarial con los países menos favorecidos. Muchos países industrializados con un nivel de renta per capita superior al 
español así lo están haciendo y España al disponer de empresas especializadas y de bienes y servicios que precisan los paises en vias de desarrollo podría evitar que la $A O D$ española revirtiera en países más ricos que el nuestro. Pero siempre desde el criterio de que la ayuda, en definitiva, debe servir, sobre todo, para favorecer el desarrollo, a corto, medio y largo plazo, de los países receptores.

\section{CONCLUSIÓN FINAL}

Ei proceso de giobalización se está acelerando en los últimos años. Se ha progresado sobre todo en las áreas de las comunicaciones, los transportes y el comercio. La intensificación de las relaciones entre los pueblos impide el aislamiento, la autosuficiencia y la independencia total. Por lo tanto, todos los países, ricos y pobres, forman parte ya de un único sistema económico internacional. Las disparidades en la distribución de la renta y la riqueza mundial deben llevar a una política global de cooperación de la que de ninguna manera es ajena ninguna población mundial.

El futuro de la Cooperación Internacional para el Desarrollo deberá tener como objetivo prioritario la pobreza, y su actuación deberá basarse en los sectores más necesitados, como son: la sanidad, la educación y la alimentación. Gobierno, empresas y las ONGD deberán colaborar estrechamente para conseguir el éxito final.

La Conclusión objetiva de esta exposición es reconocer que España está iniciando su política de ayuda al desarrollo y que todavía le queda mucho camino por recorrer para situarse entre los principales paises mundiales que se interesan realmente por aquellos otros que por su situación geográfica, su pasada historia colonial, su falta de recursos o su equivocada política económica y social están por debajo del umbral de la pobreza. El porcentaje de la Ayuda Oficial española al Desarrollo ha sido del $0,25 \%$ del PNB, en 1999/2000, y se situa por encima de la media del CAD $\left(0^{\prime} 22 \%\right)$, pero España sigue siendo el $4 .^{\circ}$ país por la cola de los 21 países donantes (la media de la UE es del $0^{\prime} 33 \%$ ). Aunque las perspectivas son de mejora, esperamos y deseamos que con la ayuda de la Administración española y de los españoles, que tari solidarios se manifiestan en los momentos de las mayores catástrofes, la situación de todos los seres humanos alcance la dignidad y el bienestar a los que tienen derecho. 